\title{
A Review of Translation Strategies of English Film Names From 1949 Onwards*
}

\author{
CHI Hui-hui, MA Shu-xia \\ University of Shanghai for Science and Technology, Shanghai, China
}

\begin{abstract}
Based on a diachronic study of translated names of English films, this paper aims to find out the preference for translation strategies in three specified periods of time, during which inseparable factors are probed into for the influences in such preference.
\end{abstract}

Keywords: English film names, translation strategy, literal translation, free translation

\section{Introduction}

The German Functionalist Translation Theory holds that the strategies of translation are interrelated with the text types and meanwhile determined by the functional purpose of the translated texts. The function of the film names involves informative function, aesthetic function, and vocative function. That is, the carefully crafted film titles not only concisely convey the content of the film, but also cater to the audience.

English film names can be translated in a number of strategies mainly including transliteration, literal translation, and free translation. Considering the distinctive social backgrounds, languages, and culture in different periods, the preference for translation strategy may be accordingly demonstrated. For instance, the film of The Heart Is a Lonely Hunter (1968) translated into 天涯何处受知心 whose translation is displayed via the strategy of free translation, the Schindler's List (1993) into 辛德勒的名单 via literal translation, and The Devil Wears Prada (2006) into 穿普拉达的女王 whose version is achieved through the combination of both free translation and literal translation.

The paper is based on a collection of over 120 English films to explore the translation preferences over three given periods: between 1949 and 1979, between 1979 and 2000, and from the beginning of 21st century till the present time. At the same time, it probes into some fundamental factors for the influences in such preferences. For the sake of comparison, the author makes the chart (see Figure 1) as a revelation of the number of English film names translated into Chinese and the correlation of translation strategy use during the three periods.

\footnotetext{
${ }^{*}$ Acknowledgement: The research is supported by the cultivation project of the humanities and social sciences fund, USST2017 (Project Item: SK17YB18).

CHI Hui-hui, master candidate, College of Foreign Languages, University of Shanghai for Science and Technology, Shanghai, China.

MA Shu-xia, M.A., associate professor, College of Foreign Languages, University of Shanghai for Science and Technology, Shanghai, China.
} 


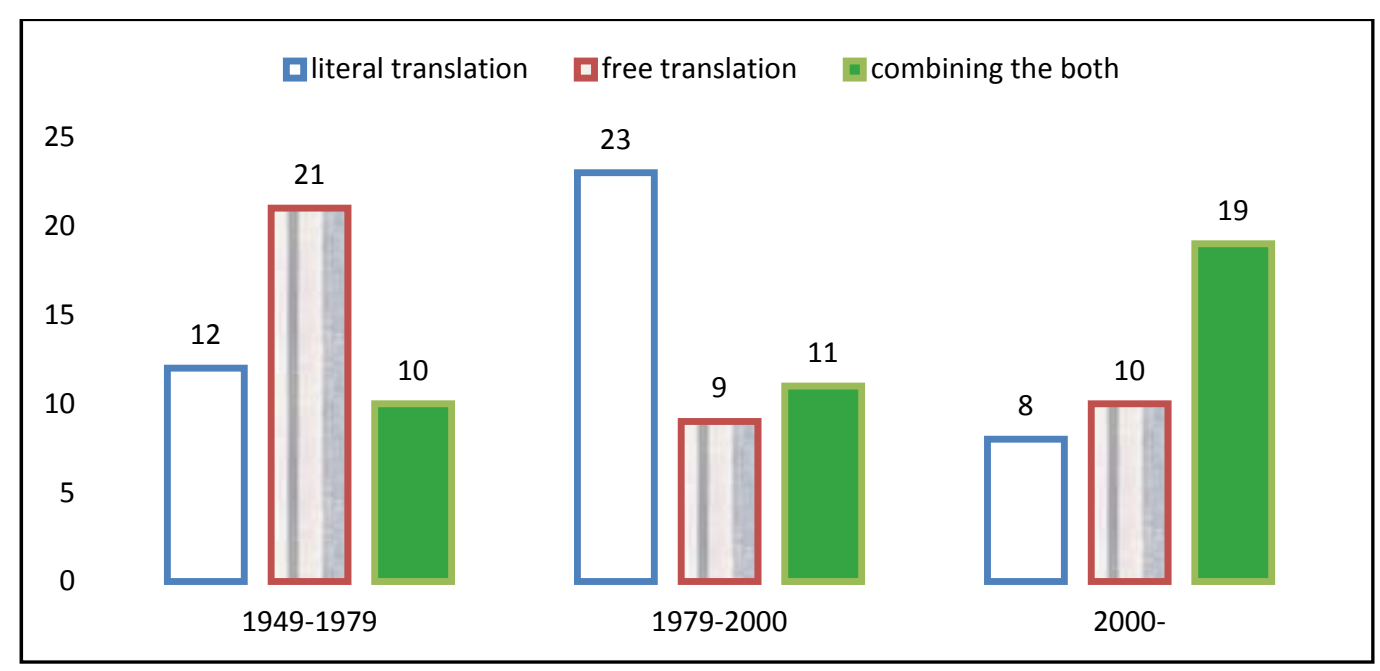

Figure 1. The Correlation of Translation Strategy Use from 1949 Onwards.

\section{A Preference for Free Translation (1949-1979)}

Between 1949 and 1979, the number of translated English film names into Chinese indicated a preference for the strategy of literal translation, accounting for $30 \%$ of the total collection of 40 films, and a preference for free translation made up $23 \%$, only $12 \%$ with a preference for the strategy use of literal and free translation.

It was obvious that the strategy of free translation was the mostly adopted one for translating English film names over this period, when the well-proportioned, melodious, and expressive Chinese four-word phrases or idioms were highly appreciated by the film translators like How to Steal a Million translated as 偷龙转风 and Seconds as 脱胎换骨 in Chinese. Looking back on the translated English film names between1949 and 1979, say, the most impressive English films Waterloo Bridge translated into 魂断蓝桥, Gone With the Wind into 乱 世佳人, The Great Waltz into 翠堤春哓, and A Song to Remember into 一曲难忘, we come to realize that these highly appreciated Chinese four-word phrases or idioms were but the embodiment of Chinese people's aesthetic values at that time.

Fu Lei, the late prestigious Chinese translation theorist once put, "In terms of effect, the process of translation should be the same as the process of painting, what we should try our best to achieve is the spiritual similarity, rather than the similarity in form” (Fu, 2014). Yan Fu (2009), another well-known late Chinese translation theorist, talked about three difficulties in his book, Evolution and Ethics, or rather three principles in translation, "faithfulness, expressiveness and elegance". Among which "elegance" is ought to be paid more attention in wording, which means choosing more appropriate words, pursuing quaintness, conciseness, and elegance in the translated versions.

Taking the film Bathing Beauty as an example, cultural metaphor usually plays an important role in embodying semantic correlation, with which in the translated names of English films it is not only helpful with an extension of semantic forms, but also an enrichment to emotions. So the Bathing Beauty was translated as 出水芙蓉, other than 浴中美人. “出水芙蓉” is a traditional Chinese idiom describing the natural beauty of a woman, which is in consistence with the image of the heroine in the film; and the Gone With the Wind was originally translated as 飘, which is not easy to understand for those who never read the novel. By comparison, the revised version 乱世佳人 made it both vivid and rich in depicting the main heroine and her living experiences as much as the film name could display. 
In view of the year of 1949to 1979, when China was in his early days of national reconstruction, for some reason, either his openness to or contact with the outside world was not so fast and desirable as it is today. Thus, the strategy of free translation is mostly applied when translating English film names into Chinese names with a clear inclination to the cognition and aesthetic appreciation of the TL (target language) audience.

\section{A Preference for Literal Translation (1979-2000)}

Compared with the period from 1949 to 1979, the results in the chart demonstrate that the strategy of literal translation was more often than not utilized for the rendered English film names into Chinese between 1979 and 2000. Say, Love at First Sight was rendered as 一见钟情, Jurassic Park as 侏罗纪公闰, and A Walk in the Clouds as 云中漫步. There were 21 English films showing a strong preference for literal translation, comprising $53 \%$ of the total collection of 40 film samples, $22 \%$ with an inclination towards free translation, and the application of the two made up $25 \%$ of the total. It can be figured out the reason that translators over this period preferred literal translation to free translation was in their pursuit of the equivalence in semantics and forms between the original and the translated version. In 1978, China began to implement the policy of reform and opening-up to the outside world. Ever since, cross-cultural communication between China and the English nations has been frequently increasing. English films as one aspect of cross-cultural communication were being introduced to domestic market in greater number than ever before. As far as the cultural communication is concerned, the application of literal translation is for sure to get TL audience well acquainted with the culture of source language (SL). In addition, more and more borrowed English expressions have greatly enriched the vocabulary of the Chinese viewers, like “Lolita” rendered as 洛丽塔, rather than 一树梨花压海棠, not only can the TL audience grasp the new borrowed word "Lolita”, but also the hidden meaning that “洛丽塔” refers to innocent and lovely maiden with mature and sexy makeup. So the same with "Titanic”, the translated version of 泰坦尼克号 would remind the TL audience of the actual ship-sinking incidents, which happened in 1912, one of the most severe marine perils in peacetime in the world.

From 1978, with the development of economy and the improvement of living standards, people were more willing to accept new words, expressions, and cultures to satisfy their curiosity. From the perspective of translators, their mission was to guide the TL audience to accept exotic cultures and, to a greater extent, match the image or imagination produced in their mind by reading the translated film names with that of the original English film names intended to create. The adoption of literal translation endowed the Chinese version with exotic color, thus broadening the TL audience's horizons. So the translation strategy was a literal translation more than a free translation over the period of 1979-2000.

\section{A Preference for Combining Free Translation and Literal Translation in 21st Century}

From the year of 2000 onwards, film translators seem to have a preference for a combined application of literal and free translation into rendering English film names into Chinese. Within the 40 selected film samples in the chart, there were almost half rendered versions achieved by means of the combined strategy, making up $48 \%$ of the total collection, $25 \%$ for literal translation, and $27 \%$ free translation respectively. Films like Saw was translated into 电锯惊魂 and Alice in Wonderland into 爱丽丝梦游仙境, whose Chinese versions well expressed the function of the text. Taking Pixar's animated movie series for example, the Chinese expression “总动员” is repeatedly used in the translated English films, such as Toy Story into 玩具总动员, Finding Nemo into 海底总动员, The Incredibles into 超人总动员, and Cars into 赛车总动员. These Chinese film names 
would easily remind the TL audience of the spirit of collectivism of their own cultural values as well as these computer-animated feature film series produced by Pixar. The addition to the translated English film names into Chinese with the expression loaded with Chinese culture has succeeded in integrating English people's social and cultural values into Chinese values, a very clear sign of cross-cultural communication in the 21st century.

By contrast, the names translated by means of pure literal translation without the added Chinese expressions may get the TL audience completely confused at their first sight, like 电锯, 爱丽丝仙境, 玩具, 海底, 超人, and 赛车. Furthermore, chances are high that these prosaic and unimaginative Chinese names would fail to arouse the Chinese viewers' interest in watching the English films. This is not only the failure of the translated English film names but the loss of film names as a vocative function, needless to say, the box-office receipts of the film. On the other hand, pure free translation cannot embody the cultural characteristics of English films.

Since the beginning of the 21st century, with the increasing frequency of cultural communication between China and Western countries, many English movies have been introduced to China, so have the Chinese movies. Chinese movies like 相爱相亲 are translated into “Love Education” and 唐人街探案2 into “Detective Chinatown", whose English versions adopted the translation strategy of combining literal and free translation, not only clarifying the content of the film, but presenting a kind of semantic equivalence to the SL text. So in view of the time from 2000, mostly adopted translation strategy is the combination of literal translation and free translation.

\section{Conclusion}

By comparing translation strategies for translating English film names from 1949 onwards, the preference for translation strategy has been remarkably revealed in three specified periods: free translation, literal translation, and then the combination of the two. Linguistically and culturally, the relatively thorough probe into and analysis of the chart above illuminate that the choice of translation strategy for English film names into Chinese is inseparable from the characteristics of the times, translators, and culture in which translators are living. For this reason, translators are not supposed to copy merely the content and form of the original text, but demonstrate the translated English language and culture with a strong sense of inspiration and aesthetic values. The name translation of English films is largely a process of re-creation, which enables the TL audience easier to understand the connotation of English language and culture. Whatever preference it is for the strategy of translating the names of English movies, the big concern is the particular period of time, in which language and culture live and the aesthetic orientation of the people prefers.

\section{References}

Du, Z. F., \& Li, Y. (2013). 基础影视翻译 (Basic Literacy in AV Translation \& Research). Zhejiang: Zhejiang University Press.

Fu, L. (2014). 译家之言: 翻译似临画 (Translator's Word: Translation is Drawing Painting). Beijing: Foreign Language Teaching and Research Press.

Fu, M. S., \& Zhou, Y. L. (2014). 英文电影片名翻译研究三十年述评 (Summary of 30-Years’ Translation Research on English Film Names). Gansu: Journal of the Northwest Adult Education.

Huxley, T. H. (2009). Evolution \& Ethics. Beijing: China Youth Press.

Nord, C. (2001). Translating as a purposeful activity: Functionalist approaches explained. Shanghai: Shanghai Foreign Language Education Press. 
Newmark, P. (2001). A textbook of translation. Shanghai: Shanghai Foreign Language Education Press.

Nida, E. A. (1993). Language, culture, and translating. Shanghai: Shanghai Foreign Language Education Press.

Wang, D., \& Sun, Y. (2011). 英语电影片名汉译中文化最佳关联策略 (The Optimal Relevant Strategy of Cultures on English Film Names). Hei longjiang: Heilongjiang Researches on Higher Education. 